\title{
Memoria y responsabilidad política
}

\section{Memory and Political Responsibility}

Luis Rodríguez Castillo

iD https://orcid.org/0000-0002-4887-823X

Universidad Nacional Autónoma de México

Centro de Investigaciones Multidisciplinarias sobre Chiapas y la Frontera Sur

Reseña:

lurodri@unam.mx

Schmucler, Héctor. (2019). La memoria, entre la política y la ética. Textos reunidos de Héctor Schmucler (1979-2015). Buenos Aires: Consejo Latinoamericano de Ciencias Sociales, Colección Legados, 656 pp., ISBN: 978-987-722-498-6.

\section{Resumen:}

La obra reseñada discute una amplia gama de temas que recupero: las relaciones entre Historia y memoria histórica, el aporte de los testimonios, los riesgos de los lugares de la memoria, la relación memoria y olvido; así como los problemas éticos que implica la decisión de qué recordar y qué olvidar. Como reflexión final se destaca la importancia de tres aspectos de esta obra de Héctor Schmucler, además de su mirada crítica sobre la estetización del terror, su propuesta de una memoria que llamó simétrica (es decir, no solo del lado de los subordinados y que sufrieron el terror de Estado), y el establecer una clara relación entre la memoria histórica y la responsabilidad política.

Palabras clave: Historia, terror, testimonio, olvido, ética.

\section{Abstract:}

The work reviewed discusses a broad spectrum of issues: the relationship between history and historical memory, the contribution made by testimonies, the risks implied by places of memory, as well as the relationship between memory and forgetting. The review's final reflection highlights the importance of three aspects in this text by Héctor Schmucler: first, his critical insight into the aestheticization of terror; second, his proposal to use what he calls symmetric memory (i.e., a memory that not only recalls those who are subordinated and suffered State terror); and finally, setting forth a clear relationship between historical memory and political responsibility.

Key Words: history, terror, testimony, forgetting, ethics. 


\section{Estructura y contenido de la obra}

a memoria, entre la política y la ética. Textos reunidos de Héctor Schmucler (1979-2015)1 integrado por 656 páginas, se divide en cuatro secciones: 1. «Textos reunidos de Héctor Schmucler» que conjunta 40 documentos entre prólogos a libros y artículos en revistas, 2. "Columnas de Héctor Schmucler en la revista La Intemperie» es una selección de 11 colaboraciones de los años 2003 y 2004 sobre asuntos de coyuntura, 3. «Intervenciones orales de Héctor Schmucler» que concentra 14 documentos, principalmente entrevistas, aunque también algunas participaciones en paneles de discusión y, 4. «Epílogo» que es su discurso al recibir el Doctorado Honoris Causa por la Universidad de Buenos Aires, en 2011, bajo el emblemático título «¿Hemos llegado?». A estas secciones le anteceden la nota de la editora Vanina Papalini y el estudio preliminar de Hugo Vezzetti.

Reconstruir una breve mirada crítica a una obra amplia es, en sí, una tarea compleja a la que se suma la dificultad de un libro que cubre una gran diversidad de temas que son, a la vez, personales y sociales (militancia, guerrilla, campos de exterminio, esperanza, exilio, cultura, terror de Estado, violencia armada, muerte, entre otros), no exentos de comentarios críticos a bienes culturales (novelas, películas, museos) que desde la perspectiva de Schmucler, llegan a estetizar y petrificar el terror y con ello a quitarle el sentido a la memoria. Las lecturas actuales de estos materiales pueden ser, igualmente, diversas. No obstante, aquí me concentro sobre las ideas planteadas por Héctor Schmucler acerca de la memoria y la responsabilidad política a la que ella nos impulsa. Aspectos que devienen en un eje de reflexión para ubicarnos en la complejidad de lo real-humano que tiene como pivote una idea que martilla pertinazmente los escritos del autor: la derrota.

\section{El testimonio, la memoria y el olvido}

La memoria de la derrota, o mejor dicho, de las derrotas -sin que esto signifique que el autor sea nihilista per se- solo es la que plantea una mirada desde las derrotas que le son personales: el exilio o el hijo desaparecido, que son

1 El lector encontrará algunas pistas biográficas e intelectuales sobre Héctor Schmucler en el estudio preliminar de Hugo Vezzetti (2019:15-48) y en la semblanza hecha por Roberto Pittaluga (2019:551 552) incluidos en el libro. También en la nota por el deceso del autor publicada por Rubén Ríos (2018). 
punto de partida para hablar de las características de la sociedad; y de ahí, a las derrotas sociales de los desaparecidos, la de la guerra de las Malvinas, la aplicación del «terror de Estado», la del proyecto de una sociedad nueva y muchas otras que son las derrotas sobre las cuales la sociedad argentina quiere instalar el olvido; pero la memoria y sus testimonios «constituyen documentos de inagotable riqueza» (Schmucler, 2019:70) y son herramienta para evitar el olvido, ese que llama a la confusión social, pero que también se hace necesario frente al terror en el que los regímenes autoritarios sumergen a una sociedad. Olvido que «es siempre ausencia de memoria en el presente [...e] impide la actualización de un relato» (Schmucler, 2019:105), la actualización del dolor, de la tristeza. "Olvido, memoria y responsabilidad se interpenetran y forman el sustento más sólido en el que se edifica lo humano» (Schmucler, 2019:121) y por eso en el presente es necesario saber buscar en la memoria.

En los documentos reunidos no encontramos un capítulo que condense una perspectiva teórico-metodológica para el abordaje de la memoria desde las ciencias sociales. Pero eso no significa que sea un libro exento de complejidades. En todo su contenido hay pistas, reflexiones, características y críticas, de carácter teórico-metodológico, sobre la memoria, el olvido, el testimonio y los lugares de memoria, por ejemplo que «la memoria es inconstante, generalmente fragmentaria, requiere de nuestro cuidado tanto como de nuestra desconfianza» (Schmucler, 2019:621) y también nos previene de los puntos ciegos provocados por el miedo que nos deja «atravesados de olvidos que oscurecen las minucias de la historia» (Schmucler, 2019:142). Sobre el olvido que afecta a la memoria afirma que es «inevitable y necesario, no es otra cosa que una interrupción de esa voluntad de recordar» (Schmucler, 2019:99) y pienso que, por ello, constituye la mayor derrota.

El autor realiza afirmaciones que sonarían a blasfemia para los principios aceptados y para quienes debaten a favor del alto valor de la memoria y el testimonio para la verdad histórica, por ejemplo, que «para la memoria no hay epistemología [... . es siempre arbitraria y siempre es verdad» (Schmucler, 2019:597, énfasis agregado). Y declara su preferencia por una visión positiva y una perspectiva desde el individualismo metodológico con su defensa de que la memoria es individual e irrepetible y que «toda generalización no es más que eso: la afirmación de valores globales que no dan cuenta de los hechos reales, históricos [...y] suele ser un sin sentido» (Schmucler, 2019:77). 
Así, vale la pregunta ¿Qué es la memoria para Schmucler? Es un artefacto, una búsqueda y un ejercicio. Ejercicio porque es reiterativa y «busca encontrar un orden entre bifurcaciones que a veces conducen a callejones cerrados». Es una búsqueda que «implica una decisión moral, una elección sobre qué retener y qué desechar en el recorrido». Es un artefacto porque la memoria es laberíntica y «hace difícil reconocer la salida» aunque de hecho la salida es lo primero que se erige y «se manifiesta como verdad» (Schmucler, 2019:161); aunque la maraña laberíntica es condición para hacer posible la verdad y, por ello, la salida es imprevisible; cada vez que se rememora un hecho hay cambios, variaciones y distintas connotaciones. No es un hecho abstracto, como una «nube metafísica» que se posa y es pensada por un grupo, sino «la coincidencia de las similares o idénticas memorias por parte de un conjunto, que justamente por eso constituye el grupo» (Schmucler, 2019:553).

Por eso el autor sugiere considerar a la memoria como un conjunto de «verdades actuantes», útiles al individuo y al grupo ya que les otorga un sentido de pertenencia dado que «pasa por las biografías» (Schmucler, 2019:505). Para el autor esta es la razón por la que la memoria «no necesita documentos», lo cual no significa que los desdeñe, pues, «sin información, sin datos, sin una transmisión de los hechos reales» (Schmucler, 2019:494) se edifican memorias falsas que resultan ineficaces. En efecto, se piensa en la utilidad de la memoria en la medida que es un instrumento para recordar y de ahí se concatenan conceptos para formar un axioma de su deber ser: recordar el pasado, no repetir errores, hacer justicia, resarcir daños, encontrar la paz, buscar la reconciliación; pero dice Schmucler, en contra de la visión romántica, que es una «ilusión» ver a la justicia que nos permite la memoria como garantía para que otros crímenes no ocurran, pues eso «es indemostrable» (Schmucler, 2019:518).

La memoria tiene ese signo distintivo: se recurre a ella frente a hechos del pasado en donde el terror de Estado y los crímenes de lesa humanidad son la constante. Pero no busca "poner en evidencia las verdades de hecho» (Schmucler, 2019:202), como lo hace la Historia, sino que busca sentido, por eso «solo es presente: no hay memoria colectiva en pasado» (Schmucler, 2019:201); no es una cuantificación de desaparecidos, tampoco una relación sobre qué pasó o cuándo pasaron los sucesos de horror, no resuelve un problema de saber cosas. Lo que sí hace la memoria, es interpelarnos «y nos exige responder por nuestros actos» (Schmucler, 2019:199). 
En suma, «la memoria es un problema moral» (Schmucler, 2019:486) que implica una decisión: "qué se recuerda y qué se olvida» (Schmucler 2019:199); asimismo, debe resolver «en qué valores se sostiene» (Schmucler, 2019:484). Por ello, es una "permanente anamnesis, es decir, una búsqueda ininterrumpida» (Schmucler, 2019:524) y, con ello, se vuelve un acto de construcción del presente que «nos obliga a pensar qué estamos haciendo hoy» (Schmucler, 2019:634). Y el interrogante sustancial de la memoria «es de distinta envergadura: ¿Cómo fue posible?» (Schmucler, 2019:202). La búsqueda de respuesta lo lleva a replantear la idea de Hannah Arendt sobre «la banalidad del mal» y que «en la banalidad está el mal». No basta con reconocer que se constituyó un aparato de exterminio y una burocracia que eximía de responsabilidad al sujeto ejecutor; hay que analizar cómo fue posible desde las ideas que le dan respaldo. Para el autor aquí está el para qué de la memoria: nos permite valorar «las circunstancias propiciadas por ideas que circulan en cierto momento y que hacen que estos hechos sean posibles» (Schmucler, 2019:626).

\section{Memoria e historia}

Para Schmucler, la relación Memoria-Historia (más allá de que ambas convocan al pasado) se condensa en que Clío es hija de Mnemósine. Valga la cita, larga, pero necesaria:

Aunque resulte aventurado, no parece un despropósito postular que la memoria rescata el conjunto de prejuicios colectivamente compartidos [...] desde la memoria, se piensa la historia y sin embargo la relación entre una y otra no deja de ser paradójica. Si bien la memoria se sustenta en la historia, donde recupera los elementos para consolidar una tradición, no la examina a partir de la verdad "objetiva" de los datos que le aporta. La historia, por su parte, se despreocupa del acto de "construir" una tradición aun cuando participa activamente en ese acto. La memoria tiene que ver con una aptitud de la voluntad. Su raigambre es ética, alienta el actuar consciente desde algunos principios. La historia carga con la responsabilidad de alimentar la memoria, pero su obligación es la verdad [...] la memoria colectiva suele legitimarse a sí misma y que no necesariamente coincide con la historia en la importancia otorgada a los hechos que registra. Y, sin embargo, esa memoria requiere clausurar cualquier posibilidad de negar lo que ha sido demostrado (Schmucler, 2019: 175-176). 
En ese constante ejercicio «la memoria posee verdades que la historia no registra» (Schmucler, 2019:424), porque la memoria es inacabable. De ahí que eso que llamamos «disputas por la memoria» no sean más que «distintas selecciones del pasado que los individuos o grupos humanos han privilegiado para salvar del olvido» (Schmucler, 2019: 361) y cotejar con la Historia. Más no solo eso, también hay esfuerzos -enmarcados en esas luchas- por objetivar a la memoria ya sea en lugares o en museos.

\section{Lugares de memoria y museos}

Schmucler interroga de qué estamos hablando cuando intentamos que un sitio, un lugar, «sea asiento de algún tipo de memoria y se muestre como aliento para una precisa forma de conciencia» (Schmucler, 2019:351) lo cual es una intención constante de los movimientos sociales que se desprenden de las luchas por la memoria; cuando tiene la particularidad de que «debería ser visto como la encarnación de una determinada memoria triunfante sobre otras memorias posibles» (Schmucler, 2019:354) y con el inconveniente de que en sí mismo carece de valor histórico y que como objetos materiales «son endebles [...] están a merced de los vientos de época» (Schmucler, 2019:404).

Memoria y lugares de memoria, tienen una particularidad como efemérides, marcan la conmemoración efímera de una fecha, pero paradójicamente «marcan la acumulación del tiempo: lo reconocible es el hecho actual, que implica el pasado» pero como hecho social tienen el valor de armonizar cierta «eticidad que acompaña a la memoria» (Schmucler, 2019:404) con el presente; pero "esto es lo indefinible, lo imposible de objetivar» (Schmucler, 2019:527). Y aquí radica la principal crítica del autor a los llamados «museos de la memoria histórica»; ya que sustituyen experiencia y vivencia, por objetos; los cuales, al final de cuentas, cristalizan el terror y hacen de este y del objeto, un fetiche para la buena conciencia de que eso no ocurrirá otra vez.

La desventaja que resulta obvia es «que otorgan valor absoluto a determinada memoria» desde una manera peligrosamente parcial de ver los sucesos y que corre el riesgo de convertirse en una repetición hueca de frases hechas. Ambas -experiencia y vivencia- hacen que la memoria se resigne «a fijar algo muerto, cuando lo deseable es que la memoria sea un permanente llamado a reflexionar sobre aquellos hechos que se recuerdan» (Schmucler, 2019:508). En estas formas, la memoria «se vuelve una abstracción evanescente, empuja al olvido» (Schmucler, 2019:386). 


\section{Memoria y responsabilidad política}

En el ensayo que inaugura la obra, el autor aborda la ironía y el cinismo implícito cuando, el mismo día que una representación de la Comisión Interamericana de Derechos Humanos (CIDH) visitaba Argentina, el gobierno de este país presentaba la ley sobre desaparecidos, -promulgada el 12 de septiembre de 1979 en la que se les declaraba como presuntos muertos. A diferencia de una visión romantizada en la que la oposición al régimen aparece como víctima, Schmucler plantea que «hubo policías sin especial identificación muertos a mansalva, hubo militares asesinados solo por ser militares, dirigentes obreros y políticos exterminados por grupos armados "revolucionarios" » y formula, entonces, las preguntas que llaman a la responsabilidad política: «¿Los derechos humanos son válidos para unos y no para otros? ¿Existen formas discriminatorias de medir que otorgan valor a una vida y no a otra? ¿Los llamados derechos humanos evocan valores ecuménicos y transhistóricos o es necesario situarlos en una visión política donde los valores se dirimen de acuerdo con la relación de fuerzas de los sectores en conflicto?» (Schmucler, 2019:54).

En este sentido, el autor plantea que la memoria, por responsabilidad política, debe ser simétrica y abordar ambos lados de los grupos en conflicto sin revictimizar a una parte y demonizar a la otra, pues hacerlo muestra los sesgos de nuestra búsqueda y los valores que los sustentan. Aboga entonces por fomentar con la memoria «dos valores o a dos instituciones centrales para pensar el lugar de los seres humanos en el mundo: la libertad y la responsabilidad» (Schmucler, 2019:561). En efecto, sostiene que la idea de sociedad es un proyecto político y a este abona la memoria en una doble vía: por un lado, al mantener viva la lucha por los derechos humanos, la justicia y muchas que superan la etapa actual y, en el presente, al igual que en el pasado, cuando se pretende «imponer como verdad obligante para todos, aparece el riesgo de las conductas autoritarias» (Schmucler, 2019:223). Esto «tiene que ver con la naturaleza misma de la sociedad democrática a construir» (Schmucler, 2019:55) y es el camino que tenemos para que «podamos confiar en alguna forma de justicia» (Schmucler, 2019:630).

En su ensayo de 1981 se logra entrever que la responsabilidad política está sujeta a un proyecto de sociedad y sobre este plantea que debe: 1. Desechar la división estructura-superestructura, 2. Incorporar la subjetividad como componente de la acción, 3. Observar procesos históricos del accionar masas-clase, así como grupos de interés e individuos que aportan irrup- 
ciones cualitativas, 4. Poner énfasis en la vida cotidiana y el modelo o estilo de desarrollo, 5. Desarrollo que debe tener en cuenta la relación de los hombres: a) entre sí y sus deseos, b) con la naturaleza como medioambiente y cosmovisión, c) con los instrumentos técnicos (Schmucler, 2019:82 y ss.). La responsabilidad política y la memoria están entretejidas porque ambas trabajan "sobre un mundo dado al que intenta conservar, modificar o rehacer» (Schmucler, 2019:258) y se trata de un trabajo que no está predeterminado, ni resulta azaroso pues su «dignidad [...] se vincula a la libertad constitutiva de lo humano» (Schmucler, 2019:259).

\section{Exhorto a la lectura}

La obra de Schmucler debe ser leída y analizada pues es una buena muestra de las reflexiones de las Ciencias Sociales argentinas y, me atrevería a aseverar, latinoamericanas de la segunda mitad del siglo XX, aunque sus búsquedas le llevan a hechos ocurridos en el mundo a lo largo del siglo pasado. Como semiólogo llama en todo momento a recuperar el sentido de las palabras. Es una obra que debemos tener en la memoria, pues nos habla de «conservar en el sentido de conservar ciertos valores que nunca tendríamos que haber abandonado; no conservar en el sentido de la política inmediata, que es mantener las estructuras injustas de una sociedad» (Schmucler, 2019:481).

Es por ello que, a pesar de fijar su atención en las derrotas que se desearía borrar de la historia, no tiene una postura nihilista, pues el reconocimiento a las memorias (en plural) es un llamado a recordar que "son elaboraciones que rescatan algo del olvido» (Schmucler, 2019:622), en las que hay una visión utópica, es decir, una «voluntad humana de despegarse de toda trascendencia para constituir, construir, un mundo autocentrado en los propios hombres» (Schmucler, 1992:8) y que la construcción de ellas es «una manera de actuar en el mundo, una idea de lo político, un proyecto de orden social» (Schmucler, 2019:605).

Nos quedan, desde luego, una serie de interrogantes que no son resueltos, antes bien, implacablemente planteados, machacados y remarcados en cada texto y en particular en la sección final (Schmucler, 2019:449 y ss.) ¿Memoria para qué? ¿Cuándo un lugar se convierte en repositorio de la memoria? ¿Qué hacen lugares y memoria, como objetos inquietantes, por -y para- un futuro mejor? En esta relación lugar-memoria considero que, siguiendo las reflexiones del autor, hay la 
intención de ciertos grupos (como los que construyen monumentos o museos) de trasladar el horror de la memoria a una Historia del Terror que queda evidenciada como una verdad absoluta.

La obra de Schmucler es una lectura necesaria en estos tiempos de paz y de un invisible enemigo global frente al cual hay que Saber-buscar-en-la-memoria. Es decir, «el saber [que] solo se realiza hoy, en el presente [...] Por eso el que sabe da cuenta de sí mismo y no solo evoca cosas» (Schmucler, 2019:104), porque la intencionalidad de la memoria se encuentra en la epojé fenomenológica en la que «si al presente se le imagina como pura direccionalidad hacia el futuro, deja de existir. El presente pierde espesor» (Schmucler, 2019:109); requiere reconocer su pasado. Una memoria que «solo dice que considera deseable que ocurra, en reemplazo de lo existente, lo que ahora es invisible, "sin lugar", utópico» (Schmucler, 2019:172). ). Por eso resulta emblemático el título de la colaboración final que cierra la obra «¿Hemos llegado?». Siempre habrá a dónde llegar (narrativa, conmoración, lugar, etc.), pero permanecerá algo que es «deseable que ocurra». Por ello, el autor comentado no es un nihilista.

A fin de cuentas, "la memoria tiene sentido en la medida que realiza la convicción de que no todo es posible» (Schmucler, 2019:212) ya que durante el proceso vivido se tuvieron derrotas y se sufrieron las consecuencias del «terror de Estado»; frente a los cuales la mayor responsabilidad política es procurar un vivir que admita alguna esperanza y, como bien advierte Héctor Schmucler, «Nada más importante, si se piensa en sostener el mundo, que lograr su permanencia como [una ética de la] memoria» (Schmucler, 2019:146).

\section{Fuentes citadas}

Pittaluga, Roberto. (2019). ¿Para que recordar? En Héctor Schmucler, La memoria, entre la política y la ética. Textos reunidos de Héctor Schmucler (1979-2015), Buenos Aires: Consejo Latinoamericano de Ciencias Sociales, pp. 551-552.

Ríos, Rubén. (2018). A los 87 años murió Héctor Schmucler, Perfil. Periodismo puro, 22 de diciembre. Disponible en <https://www.perfil.com/noticias/cultura/a-los-87-anosmurio-hector-schmucler.phtml> (consulta: 01/05/2020).

Schmucler, Héctor. (1992). Impedir la utopía, Punto de vista. Revista de cultura, XV (42), pp. 8-10. 
Schmucler, Héctor. (2019). La memoria, entre la política y la ética. Textos reunidos de Héctor Schmucler (1979-2015). Buenos Aires: CLACSO, Colección Legados, pp. 656. Vezzetti, Hugo. (2019). Héctor Schmucler: un pensamiento sobre la memoria y el mal. Estudio preliminar. En Héctor Schmucler, La memoria, entre la política y la ética. Textos reunidos de Héctor Schmucler (1979-2015). Buenos Aires: CLACSO, pp. 15- 48.

\section{Cómo citar esta reseña:}

Rodríguez Castillo, Luis. (2020). Memoria y responsabilidad política. Revista Pueblos y fronteras digital.15, pp.1-10, doi: 10.22201/cimsur.18704115e.2020.v15.519 